\title{
EMERGÊNCIA DE PLÂNTULAS E CRESCIMENTO INICIAL DE CULTIVARES DE AMENDOIM SOB RESÍDUOS DE CANA-DE-AÇÚCAR ${ }^{1}$
}

\author{
NILZA PATRÍCIA RAMOS², MARIA DO CARMO DE SALVO SOARES NOVO ${ }^{3}$, ANTÔNIO \\ AUGUSTO LAGO ${ }^{4}$, GUILHERME CALDERARI MARIN ${ }^{5}$
}

\begin{abstract}
RESUMO - O objetivo do trabalho foi avaliar o efeito da interação palha de cana-de-açúcar e aplicação de vinhaça na emergência de plântulas e no crescimento inicial de cultivares de amendoim. O experimento foi realizado em vasos dispostos em blocos ao acaso, com quatro repetições, sendo os tratamentos arranjados fatorialmente $(5 \times 2 \times 3)$ e consistindo da combinação de cinco quantidades de palha $\left(0,5,10,15\right.$ e $\left.20 \mathrm{t} \mathrm{ha}^{-1}\right)$ e a aplicação ou não de $150 \mathrm{~m}^{3} \mathrm{ha}^{-1}$ de vinhaça nas cultivares de amendoim IAC-Caiapó, Runner 886 e Tatu. Determinou-se a velocidade e a porcentagem final de emergência de plântulas, além de altura e biomassa seca da parte aérea de plantas. Conclui-se que, nas condições de casa-de-vegetação, a presença da palha de cana-de-açúcar e da vinhaça, em quantidade equivalente a $150 \mathrm{~m}^{3} \mathrm{ha}^{-1}$, em ação conjunta ou isolada, prejudicam a emergência e o crescimento de plântulas de amendoim, sendo que a cultivar Tatu é a mais tolerante em relação as cultivares 'Runner 886' e 'IAC-Caiapó'.
\end{abstract}

Termos para indexação: palha, vinhaça, oleaginosa, Arachis hypogaea L.

\section{SEEDLING EMERGENCE AND INITIAL GROWTH OF PEANUT CULTIVARS UNDER SUGAR CANE RESIDUES}

\begin{abstract}
The objective of this study was to evaluate the effect of the interaction between sugarcane mulch residue soil cover and vinasse application on seedling emergence and initial growth of peanut cultivars. A greenhouse experiment was carried out in pots with soil, in randomized complete blocks, with four replications. The treatments, arranged in a $5 \times 2 \times 3$ factorial, consisted of the combination of five quantities of sugarcane mulch residue cover $\left(0,5,10,15\right.$ and $\left.20 \mathrm{tha}^{-1}\right)$ followed by application or not of $150 \mathrm{~m}^{3} \mathrm{ha}^{-1}$ of vinasse, on soil planted with the peanuts cultivars IAC-Caiapó, Runner 886 and Tatu. The variables studied were seedling emergence speed, final emergence, plant height and dry above ground plant biomass. It was concluded that, under greenhouse conditions, the presence of sugarcane mulch residue in any of the quantities studied, and of vinasse in the quantity of $150 \mathrm{~m}^{3} \mathrm{ha}^{-1}$, either isolated or in combination, are detrimental to seedling emergence and to the initial growth of peanut. The cultivar Tatu is more tolerant to the presence of these residues on the soil surface, followed by 'Runner 886 ` and 'IAC-Caiapó'.
\end{abstract}

Index terms: sugar cane mulch residue, vinasse, oilcrop, Arachis hypogaea L.

${ }^{1}$ Submetido em 17/08/2007. Aceito para publicação em 23/01/2008. Parte das atividades desenvolvidas pela primeira autora no Instituto Agronômico de Campinas.

${ }^{2}$ Eng. Agr ${ }^{\mathrm{a}}$, Dra. Pesquisadora A. Embrapa Meio Ambiente. JaguariúnaSP. Caixa Postal 69, CEP. 13820-000.npramos@cnpma.embrapa.br

${ }^{3}$ Eng. Agra ${ }^{a}$ Dra. Pesquisadora Científica VI. IAC. Centro de Pesquisa e Desenvolvimento de Ecofisiologia e Biofísica. Campinas-SP. Caixa postal 28, CEP. 13.012-970. jpsnovo.iac.sp.gov.br

${ }^{4}$ Eng. Agro ${ }^{\circ}$ Dr. Pesquisador Científico VI. IAC. Núcleo de Pesquisa e Desenvolvimento do jardim Botânico. Campinas-SP. Caixa postal 28, CEP. 13.012-970. aalago@iac.sp.gov.br

${ }^{5}$ Biólogo, bolsa PIBIC 


\section{INTRODUÇÃO}

O aproveitamento de resíduos agroindustriais na agricultura tem aumentado de forma considerável, visando a sustentabilidade das cadeias produtivas e a redução de impactos ambientais. A vinhaça proveniente da indústria sucroalcooleira destaca-se entre esses resíduos e pode ser utilizada como fertilizante, evitando assim seu descarte como efluente, além de reduzir os gastos com insumos na produção agrícola. Também a palha, resultante da colheita mecanizada da cana-de-açúcar (Saccharum spp.) é aproveitada no ambiente agrícola, protegendo o solo da erosão e reduzindo a evaporação de água, mesmo nas estiagens (Reddy, 2003), sem considerar sua contribuição no teor de matéria orgânica e de nitrogênio no solo (Blair, 2000).

Atualmente, no Estado de São Paulo a cultura do amendoim (Arachis hypogaea L.) vem sendo cultivada com sucesso, em rotação com a cana-de-açúcar (Borsari Filho, 2006). Com a expansão dos canaviais devido ao elevado interesse comercial pelo etanol, há também a maior possibilidade de aumento da área plantada com amendoim, inclusive com o cultivo diretamente sobre a palha residual da colheita, implicando em menores custos de operação com máquinas e melhor cobertura do solo, isto sem considerar o uso da vinhaça como fonte fertilizante.

A colheita da cana-de-açúcar sem queima, chamada de "cana-crua", deixa uma camada de palha, que dependendo da cultivar e das características do solo, pode atingir até 10 $\mathrm{cm}$ de espessura. Esse resíduo altera as condições físicas do microclima local em função da qualidade e da quantidade de luz incidente, reduzindo a amplitude térmica (Vasconcelos, 2002) e afetando a emergência e o crescimento das plantas, pela interferência na dormência e germinação das sementes. (Trezzi e Vidal, 2004).

Carvalho e Nakagawa (2000) verificaram que as alterações no ambiente onde as sementes são depositadas podem prejudicar ou favorecer a emergência, pois esse processo depende da disponibilidade de água e oxigênio, além da temperatura do ambiente. Assim, modificações em algum desses fatores podem alterar o comportamento germinativo do amendoim, que exige boa disponibilidade de água e condições específicas de temperatura para uma germinação satisfatória em campo.

A presença da vinhaça adicionada ao solo também pode modificar o fluxo de emergência e o crescimento inicial de plantas, por promover a elevação do $\mathrm{pH}$ e do teor de matéria orgânica, aumentando a disponibilidade de alguns nutrientes, o poder de retenção dos cátions e estimulando ainda a atividade microbiana (Glória, 1992). Mascarenhas et al. (1994), utilizando $50 \mathrm{~m}^{3}$ ha $\mathrm{a}^{-1}$ de vinhaça como fonte de potássio na adubação de soja, não verificaram diferença na produtividade, em comparação à outras fontes de fertilizantes empregadas, indicando que esta prática não interfere significativamente no estande final da cultura e em seu estabelecimento. Fato também confirmado por Azania et al (2004), trabalhando com sementes de Sida rhombifolia e Brachiaria decumbens e doses de até $150 \mathrm{~m}^{3}$ $\mathrm{ha}^{-1}$ de vinhaça. Porém, esses autores verificaram a redução na velocidade e na porcentagem de emergência destas espécies, em relação à testemunha, nos primeiros 20 dias de desenvolvimento, sendo observada recuperação aos 40 dias após o tratamento.

Para a recomendação de uma ou outra oleaginosa a ser utilizada em rotação com a cana-de-açúcar, no sistema de manejo integrado de palha e vinhaça residuais, torna-se indispensável o conhecimento técnico sobre o crescimento inicial destas culturas nestas condições. Assim, o objetivo do trabalho foi avaliar o efeito da interação palha de cana-deaçúcar e aplicação de vinhaça na emergência de plântulas e no crescimento inicial de cultivares de amendoim.

\section{MATERIAL E MÉTODOS}

O experimento foi conduzido na casa-de-vegetação do Centro de Ecofisiologia e Biofísica do Instituto Agronômico (IAC), Campinas, SP. Foram utilizados vasos plásticos com 4,0 L de capacidade, preenchidos com 2,7 L de terra peneirada (malha metálica $2 \mathrm{~mm}$ ), proveniente de um horizonte A moderado com textura argilosa, de Latossolo Roxo, apresentando $\mathrm{pH}\left(\mathrm{CaCl}_{2}\right)=5,2$, matéria orgânica $=$ $25 \mathrm{~g} \mathrm{dm}^{-3}, \mathrm{P}$ (resina) $=1 \mathrm{mg} \mathrm{dm}^{-3}, \mathrm{~K}=0,9, \mathrm{Ca}=23, \mathrm{Mg}$ $=6, \mathrm{H}+\mathrm{Al}=28, \mathrm{SB}=29,9, \mathrm{CTC}=57,7$, expressos em $\mathrm{mmol}_{\mathrm{c}}$ $\mathrm{dm}^{-3} \mathrm{e} \mathrm{V}=52 \%$. O solo foi corrigido e adubado segundo as recomendações de Quaggio e Godoy (1997) e a irrigação foi realizada quando necessária.

Antes da instalação do experimento, foram determinadas as porcentagens de germinação de sementes e emergência de plântulas, seguindo recomendações de Brasil (1992), além da velocidade de emergência de plântulas de acordo com Maguire (1962), com a finalidade de caracterizar fisiologicamente os lotes de amendoim (Tabela 1).

Os vasos foram dispostos em blocos ao acaso, com quatro repetições, tendo os tratamentos seguido a combinação fatorial ( $5 \times 2 \times 3)$, com cinco quantidades de palha de canade-açúcar $\left(0,5,10,15\right.$ e $\left.20 \mathrm{t} \mathrm{ha}^{-1}\right)$ e a aplicação ou não do correspondente a $150 \mathrm{~m}^{3} \mathrm{ha}^{-1}$ de vinhaça residual da indústria 
TABELA 1. Caracterização inicial do potencial fisiológico das sementes de cultivares de amendoim quanto às porcentagens inicial de germinação (TG) e da emergência final (EM) e a velocidade de emergência de plântulas (IVE). Campinas-SP, 2005.

\begin{tabular}{lccc}
\hline Cultivar & TG (\%) & EM (\%) & IVE \\
\hline IAC-Caiapó & $88 \mathrm{~b}$ & $86 \mathrm{a}$ & $0,95 \mathrm{a}$ \\
Runner 886 & $92 \mathrm{a}$ & $83 \mathrm{a}$ & $0,87 \mathrm{a}$ \\
Tatu & $97 \mathrm{a}$ & $84 \mathrm{a}$ & $1,04 \mathrm{a}$ \\
\hline
\end{tabular}

Médias seguidas de mesma letra na coluna não diferem entre si pelo teste de Duncan, a 5\% de probabilidade.

sulcroalcooleira, utilizadas nas cultivares de amendoim IACCaiapó, Runner 886 e Tatu.

As sementes foram selecionadas e separadas manualmente, sendo utilizadas as retidas na peneira 24 para as cultivares IAC-Caiapó e Tatu e na peneira 22 para 'Runner 886'. Em cada vaso foram colocadas, a $3 \mathrm{~cm}$ de profundidade, 10 sementes tratadas com Thiram $0,2 \%$, sendo logo em seguida, adicionados os tratamentos com palha, e posteriormente a aplicação da vinhaça. A palha utilizada, proveniente da cultivar SP 803280, que é amplamente plantada no Estado de São Paulo, foi picada e distribuída sobre o solo, ocupando toda a superfície do vaso. A altura da camada disposta nos vasos ficou em 4, 6, 9 e $10 \mathrm{~cm}$, para as quantidades de palha correspondentes a 5, 10, 15 e $20 \mathrm{t}$ ha $^{-1}$, respectivamente. A vinhaça utilizada, proveniente de lagoas de decantação da Usina Ester em Cosmópolis, SP, apresentou em sua composição química $\mathrm{pH}=4,1, \mathrm{~N}$ total $=50,1, \mathrm{~N}$ amoniacal $=0,4, \mathrm{~N}$ nitrato $=0,2, \mathrm{~N}$ nitrito $=24,4$, $\mathrm{PO}_{4}$ total $=1.513,0, \mathrm{~K}=1.477,0, \mathrm{Ca}=525,0, \mathrm{Mg}=1.435,0$, $\mathrm{SO}_{4}=99,6$, expressos em $\mathrm{mg} \mathrm{L}^{-1}$ e $\mathrm{CE}=5,8 \mathrm{dS} \mathrm{m}^{-1}$; sendo aplicada com regador manual.

A porcentagem final de emergência de plântulas (EM) foi avaliada seguindo recomendações de Brasil (1992), contando-se o número de plântulas normais aos 15 dias após a semeadura. Concomitante a este teste, realizou-se a contagem diária do número de plântulas identificadas como normais até a estabilização desse número, para o cálculo do índice de velocidade de emergência (IVE), baseado em Maguire (1962). Para a avaliação do crescimento inicial das plantas, aos 30 dias após a semeadura, foram avaliadas: a altura (AP) em centímetro e a biomassa seca da parte aérea (BSPA), expressa em gramas e determinada após secagem em estufa, sob circulação forçada de ar a $65^{\circ} \mathrm{C}$, até a obtenção de massa constante.
Os dados foram submetidos à análise de variância empregando-se o teste $\mathrm{F}$ sendo os valores em porcentagem transformados em arco seno $\sqrt{x / 100}$ para análise estatística. Quando significativo, as médias para a diferença entre cultivares e para aplicação ou não de vinhaça foram comparadas pelo teste de Duncan. Para efeito de quantidade de palha foi usado ajuste empregando-se funções matemáticas.

\section{RESULTADOS E DISCUSSÃO}

A caracterização preliminar do potencial fisiológico dos lotes de sementes de amendoim (Tabela 1) permite observar que todas as cultivares apresentavam a taxa de germinação dentro dos padrões exigidos para comercialização. Apenas a 'IAC-Caiapó' diferiu entre as cultivares, tendo apresentado desempenho inferior às demais. Porém, para EM e IVE, não foram observadas diferenças significativas entre os lotes, com média geral de $84 \%$ e 0,95 , respectivamente. Esses resultados indicam a qualidade fisiológica adequada das sementes, com ligeira queda de vigor em relação à porcentagem de germinação, mas sem comprometimento em termos de uso dos lotes como sementes.

Não houve interação significativa para o efeito combinado de quantidade de palha adicionada, aplicação ou não de vinhaça e cultivares de amendoim. De modo geral, foi observado que as interações duplas Palha versus Vinhaça, Palha versus Cultivares e Cultivares versus Vinhaça foram significativas, sendo que apenas a BSPA não foi significativa para a interação Palha vs. Vinhaça, assim como BSPA e AP não o foram para Palha vs. Cultivares e IVE para Cultivar vs. Vinhaça.

Na Figura 1, são apresentados os resultados referentes ao efeito isolado do fator Palha nas variáveis AP e BSPA de amendoim. A AP aumentou linearmente com o acréscimo na quantidade de palha depositada sobre a superfície da terra. Entretanto, nesta mesma condição, a BSPA apresentou decréscimo linear. Esse comportamento era esperado, pois com a deposição de uma camada mais espessa de palha, a plântula tende a se alongar até alcançar a luz (Carvalho e Nakagawa, 2000), ocorrendo o estiolamento. Em condição de campo, com o estiolamento de plantas, além de menor acúmulo de biomassa, as plantas ficam mais sensíveis ao acamamento (Correia e Durigan, 2004).

Oefeito isolado da aplicação da vinhaça (Figura 2) permite observar que o IVE do amendoim foi significativamente afetado pela presença desse resíduo. Isto pode ter ocorrido em função das alterações químicas provocadas nas áreas próximas às sementes. A vinhaça promove a elevação 

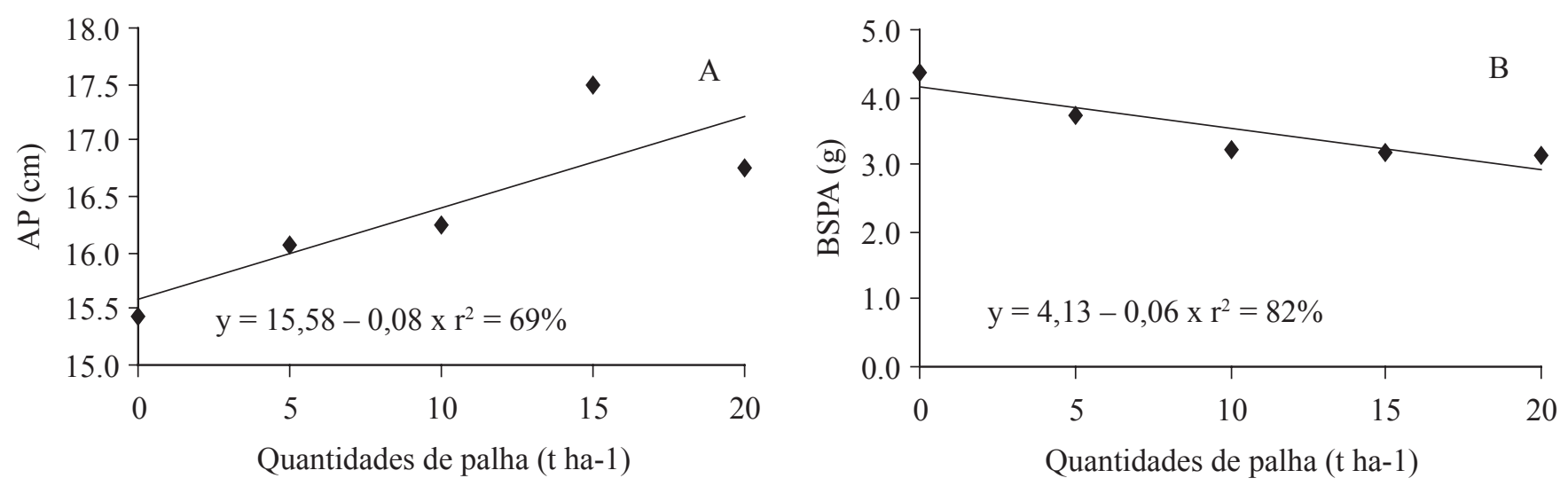

FIGURA 1. Altura média de plantas (A) e biomassa seca da parte aérea de plantas (B) de amendoim, semeado em diferentes quantidades de palha de cana-de-açúcar. Campinas-SP, 2005.

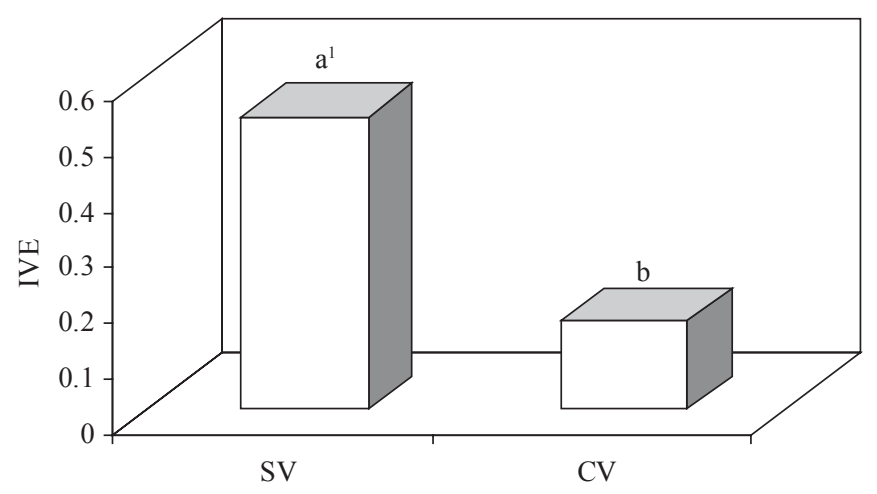

FIGURA 2. Índice de velocidade de emergência de plântulas (IVE) de amendoim semeado sem (SV) e com a aplicação de $150 \mathrm{~m}^{3} \mathrm{ha}^{-1}$ de vinhaça (CV). Campinas-SP, 2005.

do pH no solo (Leal, 1983) e também da concentração de nutrientes como potássio, magnésio e cálcio, além de alterar o teor de matéria orgânica, o poder de retenção de cátions e a capacidade de retenção de água (Quintela et al., 2002). A maior concentração de solutos na solução do solo origina um potencial osmótico mais elevado em torno das sementes, diminuindo a velocidade de absorção de água pelas sementes e portanto, atrasando o processo germinativo e a emergência de plântulas. Entretanto, segundo Brito et al. (2005), com relação ao efeito da aplicação da vinhaça ao solo, além do volume aplicado, fatores como adsorção de íons, maior ou menor migração das bases e facilidade de contacto do soluto existente neste resíduo com a superfície do solo, deve-se considerar também o tipo de solo e suas características.

No presente experimento, o solo utilizado foi peneirado e possuía textura argilosa, permitindo um alto contato do soluto da vinhaça com os colóides do solo. Assim, a adsorção dos nutrientes da vinhaça aos colóides do solo foi intensa mas como a dose aplicada foi elevada, houve ainda grande disponibilidade de solutos para a solução do solo o que interferiu no IVE. Balbo Júnior (1984) e Azania et al. (2004), avaliando sementes de plantas daninhas, também observaram atrasos na emergência de plântulas em presença da vinhaça no solo.

O atraso na emergência de plântulas expõe as sementes à ação dos patógenos de solo por maior período de tempo, o que aumenta a possibilidade de infecção e colonização do eixo embrionário (Machado, 2000). Esse atraso é ainda mais prejudicial nas sementes de amendoim, em que a extremidade da radícula fica muito próxima da superfície, que é coberta por um tegumento fino e frágil, o que favorece a infecção por patógenos e mesmo danos mecânicos.

$\mathrm{Na}$ Tabela 2, são apresentados os valores médios de EM e IVE, referentes ao efeito de Palha vs. Cultivares, que foi altamente significativo. Houve decréscimo dessas duas variáveis com o aumento da quantidade de palha adicionada ao solo, independente da cultivar estudada, com maior ou menor interferência desse último fator apenas na intensidade dessa redução. Assim, na presença de palha de cana-deaçúcar dentro de cada cultivar de amendoim, verificou-se para 'IAC-Caiapó' e 'Runner 886', que houve decréscimo linear na EM e no IVE, com o aumento da quantidade mantida sobre a terra. Com a adição do equivalente a $20 \mathrm{t}$ $\mathrm{ha}^{-1}$ de palha (camada de $10 \mathrm{~cm}$ ) houve redução de $96 \%$ e $88 \%$ na EM e $94 \%$ e $81 \%$ no IVE, respectivamente para cada cultivar. Entretanto, na 'Tatu' o IVE foi reduzido em 58\% e a EM, em apenas $44 \%$.

Comparando-se as cultivares dentro de cada quantidade de palha mantida sobre a terra, verificou-se que, de modo 
TABELA 2. Valores médios da porcentagem de emergência de plântulas (EM) e índice de velocidade de emergência de plântulas (IVE), referentes aos efeitos da interação Palha vs. Cultivares, na cultura do amendoim. Campinas-SP, 2005.

\begin{tabular}{|c|c|c|c|c|c|c|}
\hline \multirow{2}{*}{ Cultivares } & \multicolumn{6}{|c|}{ Quantidade de palha adicionada ao solo $\left(\mathrm{t} \mathrm{ha}^{-1}\right)$} \\
\hline & 0 & 5 & 10 & 15 & 20 & Equações de ajuste e coef. de determinação em \% \\
\hline \multicolumn{7}{|c|}{ Emergência de plântulas (\%) } \\
\hline IAC-Caiapó & $64,6 \mathrm{a}^{1}$ & $37,8 b$ & $23,2 \mathrm{a}$ & $8,4 \mathrm{~b}$ & $2,6 \mathrm{~b}$ & $Y=51,04-2,20 \mathrm{x} \mathrm{r}^{2}=98,6$ \\
\hline Runner 886 & $60,8 \mathrm{a}$ & $27,0 \mathrm{~b}$ & $16,5 \mathrm{a}$ & $7,2 \mathrm{~b}$ & $7,3 b$ & $Y=50,4-3,91 \times r^{2}=98,9$ \\
\hline Tatu & $60,5 \mathrm{a}$ & $57,1 \mathrm{a}$ & $25,9 \mathrm{a}$ & $48,4 \mathrm{a}$ & $33,9 \mathrm{a}$ & $Y=51,22 \cdot 0,97^{x} r^{2}=68,0$ \\
\hline $\mathrm{C} \times \mathrm{P}$ & \multicolumn{6}{|c|}{$442,11^{* * 2}$} \\
\hline \multicolumn{7}{|c|}{ IVE } \\
\hline Caiapó & $0,66 a$ & $0,39 b$ & $0,28 \mathrm{a}$ & $0,18 \mathrm{~b}$ & $0,04 \mathrm{~b}$ & $Y=0,60-0,03 \times r^{2}=98,8$ \\
\hline Runner 886 & $0,64 \mathrm{a}$ & $0,31 b$ & $0,23 \mathrm{a}$ & $0,10 \mathrm{~b}$ & $0,12 b$ & $Y=0,53-0,02 \times \mathrm{r}^{2}=82,1$ \\
\hline Tatu & $0,69 \mathrm{a}$ & $0,53 \mathrm{a}$ & $0,28 \mathrm{a}$ & $0,41 \mathrm{a}$ & $0,29 \mathrm{a}$ & $Y=0,68-0,04 x+0,001 x^{2} r^{2}=82,9$ \\
\hline $\mathrm{C} \times \mathrm{P}$ & \multicolumn{6}{|c|}{$0,04^{* *}$} \\
\hline
\end{tabular}

${ }^{1}$ Médias seguidas de mesma letra na coluna não diferem entre si pelo teste de Duncan, a 5\% de probabilidade

${ }^{2}$ Valores dos quadrados médios, referentes à Análise de Variância e sua significância.

geral, 'Tatu' foi a menos afetada por esse resíduo, não havendo diferença entre as outras duas cultivares. Portanto, essa cultivar pode ser a mais indicada para cultivo em áreas de reforma de canavial, após colheita mecânica de genótipos que deixam elevada quantidade de palha sobre o solo.

A deposição da palha sobre o solo ocasiona mudança nas condições químicas, físicas e biológicas do ambiente edáfico, e dependendo da espécie, pode afetar a emergência e o crescimento das plantas. Com a adição da palha há tendência de redução na absorção de calor pelo solo durante o dia (Teasdale, 1996), interferindo na amplitude térmica entre o período diurno e noturno, o que em muitos casos retarda sensivelmente a velocidade de emergência das sementes, fato este também observado nesse experimento.
O efeito da interação Vinhaça vs Cultivares é apresentado na Tabela 3. Houve ação inibitória da vinhaça sobre o desenvolvimento inicial do amendoim em todas as cultivares estudadas. As maiores diferenças foram observadas na EM, ocorrendo reduções de $91 \%$, 86\% e de $58 \%$ nas cultivares IAC-Caiapó, Runner 886 e Tatu, respectivamente. O efeito tóxico da vinhaça pode estar associado à elevada quantidade de solutos e de outros compostos orgânicos adicionados à terra que podem causar danos ao embrião do amendoim. Neste contexto, Welbaum e Bradford (1990) observaram que as sementes de melão podem ser embebidas em soluções salinas de alta concentração sem que haja danos celulares, pois apresentam tecidos semi-permeáveis envolvendo o embrião, assim como as de tomate, alface e pimentão; entretanto,

TABELA 3. Valores médios de emergência de plântulas (EM), altura média de plantas (AP) e biomassa seca da parte aérea de plantas (BSPA), referentes aos efeitos da interação Cultivares vs. Vinhaça, na cultura do amendoim. Campinas-SP, 2005.

\begin{tabular}{|c|c|c|c|c|c|c|}
\hline \multirow[t]{2}{*}{ Cultivares } & \multicolumn{2}{|c|}{$\operatorname{EM}(\%)$} & \multicolumn{2}{|c|}{$\mathrm{AP}(\mathrm{cm})$} & \multicolumn{2}{|c|}{ BSPA $(g)$} \\
\hline & $\mathrm{SV}^{1}$ & $\mathrm{CV}^{2}$ & SV & $\mathrm{CV}$ & SV & $\mathrm{CV}$ \\
\hline IAC-Caiapó & $46 \mathrm{Ab}^{3}$ & $4 \mathrm{Bb}$ & $17,1 \mathrm{Ab}$ & $11,6 \mathrm{Bb}$ & $3,8 \mathrm{Ab}$ & $2,8 \mathrm{Bb}$ \\
\hline Runner 886 & $49 \mathrm{Ab}$ & $7 \mathrm{Bb}$ & $18,4 \mathrm{Ab}$ & $11,8 \mathrm{Bb}$ & 4,4Aa & $2,1 \mathrm{Bc}$ \\
\hline Tatu & 64Aa & $27 \mathrm{Ba}$ & $21,9 \mathrm{Aa}$ & $17,5 \mathrm{Ba}$ & 4,7Aa & $3,3 \mathrm{Ba}$ \\
\hline $\mathrm{C} \mathrm{V}^{5}$ & \multicolumn{2}{|c|}{$323,14^{* 4}$} & \multicolumn{2}{|c|}{$12,03^{*}$} & \multicolumn{2}{|c|}{$513,42^{* *}$} \\
\hline
\end{tabular}

${ }^{1} \mathrm{SV}$ - sem aplicação de vinhaça; ${ }^{2} \mathrm{CV}$ - com aplicação de $150 \mathrm{~m}^{3}$ ha ${ }^{-1}$ de vinhaça; ${ }^{3}$ Médias seguidas de mesma letra maiúscula na linha e minúscula na coluna não diferem entre si pelo teste de Duncan, a 1\% (*) e 5\% (**)de probabilidade; ${ }^{4}$ Valores dos quadrados médios, referentes à Análise de Variância e sua significância. 

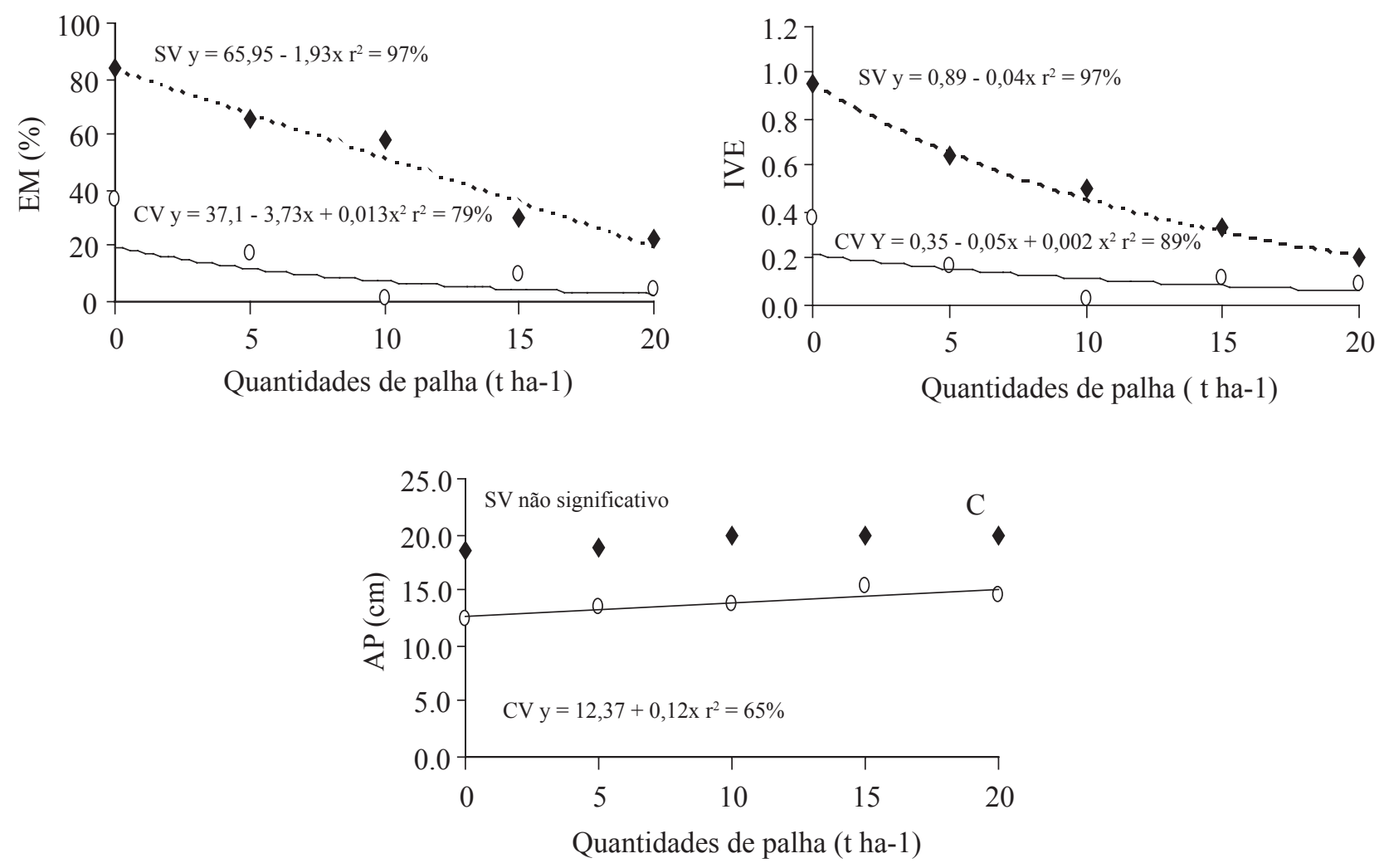

FIGURA 3. Porcentagem de emergência de plântulas (A), índice de velocidade de emergência (B) e altura média de plantas (C), referentes aos efeitos da interação Palha vs. Vinhaça, na cultura do amendoim, sendo SV-sem adição de vinhaça e CV- com adição de vinhaça Campinas-SP, 2005.

nas de brócolos que apresentam tecidos permeáveis a sais (Welbaum et al., 1998), há elevada intoxicação celular.

De modo geral, a cultivar Tatu apresentou valores mais elevados de EM, AP e BSPA que os outros genótipos, tanto na presença como na ausência da vinhaça (Tabela 3). Não houve diferença na EM e na AP entre as cultivares IAC-Caiapó e Runner quando tratadas ou não com esse resíduo. Com relação à variável BSPA, na ausência da vinhaça, o pior desempenho foi observado para 'IAC-Caiapó', fato não observado na presença deste resíduo, onde a 'IAC-Caiapó' apresentou BSPA superior à da 'Runner 886', mas inferior a da 'Tatu'. Christoffoleti e Bacchi (1985) também observaram reduções na emergência de plântulas de D. horizontalis, Cyperus rotundus, S. rhombifolia e Emilia sonchifolia, em solos tratados com doses de vinhaça.

O melhor desempenho da cultivar Tatu pode estar relacionado ao seu hábito de crescimento, que é classificado como ereto, o que justifica a sua superioridade em altura no mesmo período de tempo em relação à 'IAC-Caiapó' e à 'Runner 886' (Tabela 3), ambas com hábito rasteiro. Esse comportamento pode ser um dos responsáveis pela sua maior tolerância, tanto à presença da palha, como da vinhaça no solo. Neste trabalho, optou-se em comparar os parâmetros AP e BSPA entre cultivares de hábito de crescimento diferenciado, justamente para verificar se a presença dos resíduos seria ou não restritiva ao crescimento de genótipos distintos, lembrando que entre os critérios de escolha das cultivares considerou-se também o maior uso em áreas de reforma de cana-de-açúcar, atualmente.

Com relação ao efeito de Palha vs Vinhaça, os resultados são apresentados na Figura 3. Os tratamentos sem vinhaça (SV) foram significativamente superiores aos com presença da vinhaça $(\mathrm{CV})$ em todos os níveis de palha para as variáveis EM, IVE e AP, variando apenas a intensidade desse efeito, em função da maior ou menor camada da palha. Para EM, houve decréscimo linear com o aumento na camada de palha, sendo que a redução foi de $76 \%$ para os tratamentos SV e 75\% nos CV. O IVE foi drasticamente reduzido no tratamento com palha, tanto na presença como na ausência da vinhaça sendo o efeito mais severo na ausência deste resíduo, com redução de $79 \%$. Na presença da vinhaça, a redução no IVE foi de 
$76 \%$, com valores mais baixos mesmo no tratamento sem palha $(0,37)$. A adição de palha não interferiu na AP, para os tratamentos SV; por outro lado, nos CV houve interferência, com acréscimo exponencial em função do aumento na camada de palha sobre o solo.

Como consideração final, cabe destacar que a experimentação em campo é sugerida para a continuidade desta linha de estudos, com a finalidade de verificar, principalmente, os efeitos da adição da vinhaça sobre a cultura do amendoim, de forma mais consistente. Uma vez que os efeitos observados em experimentos de vasos podem, muitas vezes, ser mais restritivos em função da menor lixiviação de compostos para o perfil do solo.

\section{CONCLUSÕES}

Em condições de casa-de-vegetação é possível concluir que a presença da palha de cana-de-açúcar e da vinhaça, em quantidade equivalente a $150 \mathrm{~m}^{3} \mathrm{ha}^{-1}$, em ação conjunta ou isolada, é prejudicial à emergência de plântulas e ao crescimento inicial de cultivares de amendoim;

Existe resposta diferenciada de cultivares à presença de palha e vinhaça, sendo a cultivar Tatu é a mais tolerante em relação a 'Runner 886' e a 'IAC-Caiapó'.

\section{REFERÊNCIAS}

AZANIA, A.A.P.M.; AZANIA, C.A.M.; MARQUES, M.O.; PAVANI, M.C.M.D. Emergência e desenvolvimento de guanxuma (Sida rhombifolia), capim-braquiária (Brachiaria decumbens) e cana-de-açúcar (Saccharum spp.) influenciados por subprodutos da destilação do álcool. Planta Daninha, Viçosa, v. 22, p.331-336, 2004.

BALBO JR., L. Estudos preliminares dos efeitos da vinhaça sobre a emergência e desenvolvimento inicial de plantas daninhas. I - Fedegoso (Cassia tora L.). $41 \mathrm{f}$. Monografia (Trabalho de graduação em Agronomia). Faculdade de Ciências Agrárias e Veterinárias, Universidade Estadual Paulista, Jaboticabal, 1984.

BLAIR, N. Impact of cultivation and sugar-cane green trash management on carbon fractions and aggregate stability for a Chromic Luvisol in Queensland, Australia. Soil \& Tillage Research, Ohio, v.55, p.183-191, 2000.

BORSARI FILHO, S. Potencial da cultura do amendoim como fonte de matéria-prima para o Programa Nacional de Produção e Uso de Biodiesel. In: CÂMARA, G.M.S.; HEIFFIG, L.S. Agronegócios de plantas oleaginosas matérias-primas para biodiesel. Piracicaba: FEALQ. 2006. p.43-55, 2006.
BRASIL. Ministério da Agricultura e Reforma Agrária. Regras para análise de sementes. Brasília: AGIPLAN, 1992. 365p.

BRITO, F.L.; ROLIM, M.M.; PEDROSA, E.M.R. Teores de potássio e sódio no lixiviado e em solos após a aplicação de vinhaça. Revista Brasileira de Engenharia Agrícola e Ambiental, Campina Grande, v.9, suplemento, p.52-56, 2005 .

CARVALHO, N.M. ; NAKAGAWA, J. Sementes: ciência, tecnologia e produção. Jaboticabal: FUNEP, 2000. 650p.

CHRISTOFFOLETI, P.J.; BACCHI, O.O.S. Efeito da aplicação de vinhaça sobre a população e controle químico das plantas daninhas na cultura da cana-de-açúcar (Saccharum spp). Planta Daninha, Viçosa, v.8, p.60-70, 1985.

CORREIA, N.M. ; DURIGAN, J.C. Emergência de plantas daninhas em solo coberto com palha de cana-de-açúcar. Planta Daninha, Viçosa, v.22, p.11-17, 2004.

GLÓRIA, N. A. Uso agronômico de resíduos. In: REUNIÃO BRASILEIRA DEFERTILIDADEDO SOLOENUTRIÇÃO DE PLANTAS, 20, 1992. Piracicaba. Anais... Piracicaba: ESALQ/USP, 1992. p.1-17.

LEAL, J. R. Potencial redox e pH: variações em um solo tratado com vinhaça. Revista Brasileira de Ciência do Solo, Viçosa, v.7, p.257-261, 1983.

MACHADO, J.C. Patologia de sementes: significado e atribuições. In: CARVALHO, N.M.; NAKAGAWA, J. Sementes: ciência, tecnologia e produção. 4.ed. Jaboticabal: FUNEP, 2000. 588p.

MAGUIRE, J.D. Speed of germination aid in selection and evaluation for seedling and vigor. Crop Science, Madison, v.2, p.176-177, 1962.

MASCARENHAS, H.A.A.; TANAKA, R.T.; PEREIRA, J.C.V.N.A.; GALLO, P.B.; BATAGLIA, O.C. Efeito de adubos potássicos na produção de soja. Scientia Agricola, Piracicaba, v.51, p.82-89, 1994.

QUAGGIO. J.A. ; GODOY, I.J. Amendoim. In: RAIJ, B.; CANTARELLA, H.; QUAGGIO, J.A.; FURLANI, A.M.C.(Eds.) Recomendações de adubação e calagem para o estado de São Paulo, $2^{\text {a }}$ ed. Campinas, Instituto Agronômico ; Fundação IAC, 1997. p.285.

QUINTELA, A.C.R.; ANDRADE, L.A.B.; CORRÊA, J.B.D.; RESENDE, P.M.; VIEIRA, G.G. Controle de plantas daninhas em cana crua (cultivar RB835089) no sistema integrado palhiço, herbicida e vinhaça. STAB, v.20, p.38-42, 2002.

REDDY, K.N. Impact of rye cover crop and herbicides on weeds, yield, and net return in narrow-row transgenic and 
conventional soybean (Glycine max). Weed Technology, v.17, p.28-35, 2003.

TEASDALE, J.R. Contribution of cover crops to weed management in sustainable agricultural systems. Journal of Production Agriculture, v.9, p.475-479, 1996.

TREZZI, M.M.; VIDAL, R.A. Potencial de utilização de cobertura vegetal de sorgo e milheto na supressão de plantas daninhas em condição de campo: II - Efeitos da cobertura morta. Planta Daninha, Viçosa, v.22, p.1-10, 2004.

VASCONCELOS, A.C.M. Desenvolvimento do sistema radicular da parte aérea de socas de cana-de-açúcar sob dois sistemas de colheita: crua mecanizada e queimada manual. 2002. 140f. Tese (Doutorado em Produção Vegetal) - Faculdade de Ciências Agrárias e Veterinárias Universidade Estadual Paulista, Jaboticabal, 2002.

WELBAUM, G.E.; SHEN, Z.; OLUOCH, M.O.; JETT, L.W. The evolution and effects of priming vegetables seeds. Seed Technology, Wallingford, v.20, p.209-235, 1998.

WELBAUM, G.E.; TISSAOWI, T.; BRADFORD, K.J. Water relations of seed development and germination in muskmelon (Cucumis melo L.). IV. Characteristics of perisperm during development. Plant Physiology, Bethesda, v.92, p.1038-1045, 1990. 